\title{
Father for the first time - development and validation of a questionnaire to assess fathers' experiences of first childbirth (FTFQ)
}

\author{
Åsa Premberg ${ }^{*}$, Charles Taft, Anna-Lena Hellström and Marie Berg
}

\begin{abstract}
Background: A father's experience of the birth of his first child is important not only for his birth-giving partner but also for the father himself, his relationship with the mother and the newborn. No validated questionnaire assessing first-time fathers' experiences during childbirth is currently available. Hence, the aim of this study was to develop and validate an instrument to assess first-time fathers' experiences of childbirth.

Method: Domains and items were initially derived from interviews with first-time fathers, and supplemented by a literature search and a focus group interview with midwives. The comprehensibility, comprehension and relevance of the items were evaluated by four paternity research experts and a preliminary questionnaire was pilot tested in eight first-time fathers. A revised questionnaire was completed by 200 first-time fathers (response rate $=81 \%$ ) Exploratory factor analysis using principal component analysis with varimax rotation was performed and multitrait scaling analysis was used to test scaling assumptions. External validity was assessed by means of known-groups analysis.
\end{abstract}

Results: Factor analysis yielded four factors comprising 22 items and accounting $48 \%$ of the variance. The domains found were Worry, Information, Emotional support and Acceptance. Multitrait analysis confirmed the convergent and discriminant validity of the domains; however, Cronbach's alpha did not meet conventional reliability standards in two domains. The questionnaire was sensitive to differences between groups of fathers hypothesized to differ on important socio demographic or clinical variables.

Conclusions: The questionnaire adequately measures important dimensions of first-time fathers' childbirth experience and may be used to assess aspects of fathers' experiences during childbirth. To obtain the FTFQ and permission for its use, please contact the corresponding author.

Keywords: Fathers, Childbirth, Questionnaire, Validity, Reliability

\section{Background}

Becoming a father for the first time is a central episode in life [1-3]. Since fathers entered the delivery room some decades ago, their role has mainly been to give emotional support to the birth giving woman [4,5]. Nonetheless, attending childbirth also has benefits for the father. For example, it has been shown to facilitate the transition to fatherhood [6,7], solidify the father's relationship with his

\footnotetext{
* Correspondence: asa.premberg@vgregion.se

Institute of Health and Care Sciences, Sahlgrenska Academy at Gothenburg University, Box 457, SE-40530 Gothenburg, Sweden
}

birth giving partner [8-10], and promote early attachment between father and infant and their bonding $[1,11]$.

On the other hand, fathers sometimes find childbirth more emotional and demanding than expected [12] and their need of personal support is well recognized $[13,14]$. In interviews with first-time fathers, we found that fathers oftentimes feel compelled to hide their feelings of insecurity, nervousness, irritation and frustration behind a confident, calm façade when supporting their partner during childbirth [15-17]. Some fathers also feel that they are unimportant during childbirth and feel ignored by midwives and other staff members. Fathers also frequently consider that the information they

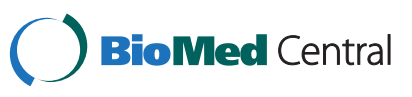

(c) 2012 Premberg et al.; licensee BioMed Central Ltd. This is an Open Access article distributed under the terms of the Creative Commons Attribution License (http://creativecommons.org/licenses/by/2.0), which permits unrestricted use, distribution, and reproduction in any medium, provided the original work is properly cited. 
receive from midwives is conciliatory or erroneous, which has also been found in earlier research on fathersto-be [18].

Little attention has focused on how such experiences impact on the fathers' supportive role during labour and childbirth or subsequently on their role as fathers after childbirth. However, two recent studies indicate that fathers' negative experiences during childbirth may be associated with depressive symptomatology after childbirth $[19,20]$. There is therefore a need to further investigate fathers' childbirth experiences both to address the fathers own needs of support during childbirth and to identify fathers whose needs of support have not been met.

Questionnaires for assessing fathers' experiences of the pregnancy period and childbirth have been developed [21-26]; however, there is only one validated instrument for assessing fathers' experiences during labour and birth [6]. Given that first-time fathers are presumably particularly vulnerable during childbirth, an instrument designed specifically for assessing their experiences seems called for. The aim of this study was thus to develop and validate an instrument to assess first-time fathers' experiences of childbirth (FTFQ).

\section{Methods}

\section{Design and ethical considerations}

In this study, a methodological and developmental design was used to determine the construct validity and the internal consistency reliability of a questionnaire to assess first-time fathers' experiences of childbirth. Permission to undertake the study was obtained from the responsible managers at the hospitals involved. The study was approved by the Regional Ethical Review Board in Gothenburg and was conducted in accordance with ethical principles of the Declaration of Helsinki [27].

\section{Instrument development}

Procedures for developing the instrument encompassed three stages, 1. identification of important domains of the first-time father's experiences of childbirth and generation of items to represent the domains, 2. evaluation of comprehensiveness, comprehension and relevance of the items and 3. validation of the scales.

\section{Identification of core domains}

Five domains were identified from our previous interview studies with first-time fathers: 'expectations and wishes', 'information,' 'support to the woman,' 'emotional support' and 'comfort' [15-17]. A literature search in Pub Med, Cinahl and Scopus using the keywords father, childbirth and questionnaire were conducted to identify other possible domains. A focus group interview was conducted with eight experienced female midwives to gain information about midwives perceptions of the fathers' presence in labour and birth. The midwives were encouraged to freely discuss their impressions about how fathers experienced birth and fathers' needs for support.

\section{Item generation}

Statements illustrating the five salient domains were extracted verbatim from our interviews with first-time fathers by two of the authors ( $\mathrm{P}$ and MB) $[15,16]$. Additional items were gleaned from our focus group interviews with midwives and from discussions with a panel of four experts in paternity research from different academic disciplines (midwifery, sociology and psychology).

\section{Item evaluation}

The resulting item pool was first scrutinized by the expert panel for comprehensiveness, relevance and comprehensibility. After modifications based on the panel's recommendations, a preliminary version of the questionnaire was drafted. A 4-point Likert response scale was used (strongly agree (1) agree (2) slightly agree (3) disagree (4)).

The questionnaire was mailed to a pilot group of eight first-time fathers. They were asked to fill in the questionnaire and to rate the relevance and comprehensibility of each of the items on a 4-point scale. Items with low relevance ratings were omitted and those with low comprehensibility ratings were reworded. Thereafter the expert panel re-evaluated the questionnaire.

\section{Instrument validation}

\section{Setting and study sample}

The study population comprised first-time fathers whose partner had given birth at one of four delivery wards at two major hospitals (one urban and one provincial) in southwestern Sweden between November 26 and December 24, 2009 (urban hospital) or between November 26 and January 9, 2010 (provincial hospital). As only mothers' postal addresses are documented in birth records in Sweden, first-time fathers were contacted via their birth giving partners. In February 2010, questionnaires were sent to 306 mothers who met the following inclusion criteria: first-time mothers with a vaginal birth (normal or instrumental) or an acute caesarean, who had reported a man as their closest relative and whose infant had an Apgar score over five assessed after five minutes. The mothers were mailed a letter requesting them to give the questionnaire to the father of the newborn. The fathers were requested to complete and return the paper questionnaire or to complete an electronic version via the internet. Only first-time fathers who were Swedish speaking and who had attended childbirth were included.

\section{Statistical and psychometric analyses}

Descriptive statistics were computed to characterize item score distributions. Item response completeness and 


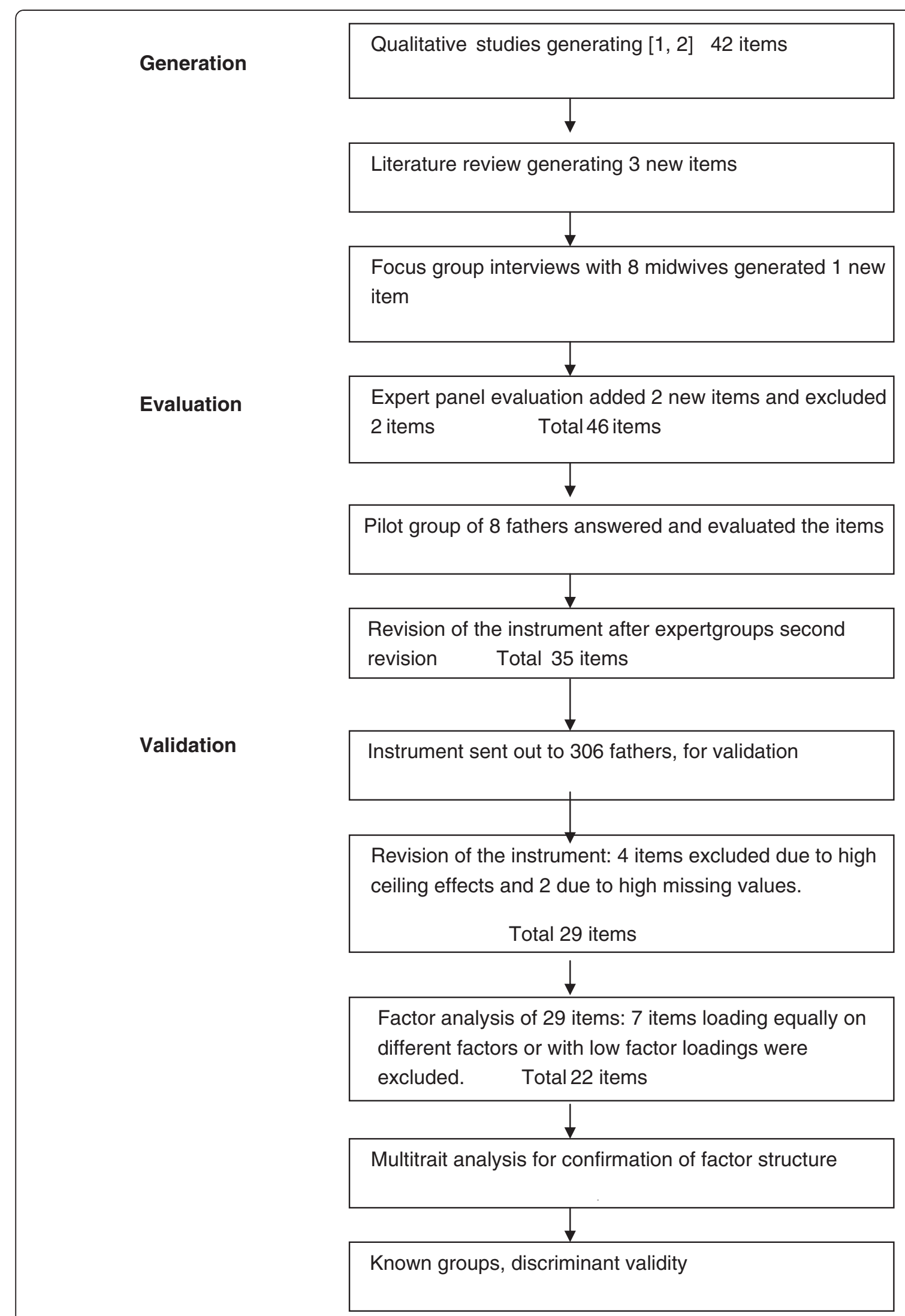

Figure 1 Flow chart of the development and validation of the First-Time Fathers Questionnaire. 
frequency were examined. Items with high missing values or ceiling/floor effects ( $>90 \%$ of the ratings in the highest vs. lowest response categories) were excluded from the subsequent analysis since they may reduce the sensitivity and responsiveness of the scale [28].

A principal components analysis was performed to explore the construct validity of the questionnaire. A varimax rotation was used since the correlations between the components were low $(<0.3)$. Items with maximum loadings less than 0.40 were excluded from subsidiary factor analysis. The Kaiser rule (eigenvalue $>1.0$ ) was applied for determining the number of dimensions to extract, along with the criteria that the factors should be interpretable from a clinical perspective (Figure 1).

Multitrait-scaling analysis was performed to confirm the derived factor structure and to test scaling assumptions for aggregating item ratings of the dimensions. Four assumptions were tested: 1) item internal consistency (item-hypothesized scale correlations ${ }^{3}>0.40$ and Cronbach's alpha $\left.{ }^{3} 0.70\right), 2$ ) item discriminant validity (itemhypothesized scale correlation > item-other scale), 3) equal item-hypothesized scale correlation (item-scale correlations roughly the same for all items in scale), 4) item equal variance (variances of items in hypothesized scale roughly equal).

Item ratings were aggregated to scale scores for each respondent using the half scale method, i.e., mean values were computed when the respondent had answered at least half of the items in the scale [28].

Known-groups validation [28,29] was used to assess the discriminant validity of the questionnaire, i.e. the ability of the questionnaire to distinguish between subgroups known to differ on key socio demographic or clinical variables. Based on previous research $[23,30]$, it was hypothesized that first-time fathers whose child was delivered with caesarean section would express more negative attitudes than fathers whose child was delivered vaginally. Moreover, it was expected that young fathers $[31,32]$ and immigrant fathers [33,34] would be more distressed, unprepared and in need of more support during childbirth. One-way analysis of variance (ANOVA) was used to compare scale scores between groups and Tukey post hoc tests were used. A 5\% significance level was used throughout.

Descriptive statistics (ANOVA) and factor analyses were conducted using SPSS 18 statistical software (SPSS Inc, Chicago, Ill, USA) and the MAP-R program [35] was used for multitrait-scaling analysis.

\section{Results}

Instrument development

Domain identification and item generation

The literature search for domains of fathers' experiences of childbirth yielded 94 articles, of which 21 were judged to be relevant. Articles were included if they concerned fathers experiences of childbirth and articles in which fathers were not the main focus were excluded. On the other hand, articles about fathers which were related to childbirth but did not focus on labour and birth. Hence, articles that focused on special medical conditions or/and disability of the child were omitted. The literature search yielded no additional domains to supplement the five domains found in our previous interview studies. The focus group interview with the midwives suggested that the identified domains adequately covered fathers' experiences.

Approximately nine statements representing each domain were extracted verbatim from the interviews. Thus the initial item pool comprised 45 items. The focus group interview added one new item. The evaluation by the expert panel excluded two items, primarily due to overlapping of item content. Based on the panel discussion, two new items were drafted to broaden the coverage of the domains and a number of items were modified to improve item comprehension.

A preliminary version of the questionnaire was drafted comprising 46 items with a 4-point Likert response scale strongly agree (1) agree (2) slightly agree (3) disagree (4). Pilot testing in a group of eight first-time fathers resulted in the deletion of 11 items due to low relevance ratings and in the rewording of several items to improve comprehensibility.

The final questionnaire thus comprised 35 items with an additional 8 questions about how the fathers prepared for birth (2 questions), mode of birth, ethnic background (2 questions), age, level of education and marital status.

\section{Instrument validation}

\section{Setting and study sample}

The questionnaire was mailed via the mothers to 306 first-time fathers. Ten letters were undeliverable and 50 fathers did not meet inclusion criteria (Figure 2). Of the remaining 246 fathers, $81 \%(n=200)$ returned the questionnaire after two reminders, 59 of them via the website. The respondents median age was 31 years (Mean 31.8, $\mathrm{SD}=5.6$ ) with a range of $19-55$ years, which corresponds to the national average of first-time fathers in Sweden [36]. In total, $18 \%(n=33)$ were born outside Sweden (national average $200814 \%)$, while 24\% $(n=46)$ had one or two parents born outside Sweden (no national average available). A slightly greater proportion of the participants had high school or university education than the national average (Table 1$)$. Nearly all fathers $(n=185)$ resided with the child's mother when they answered the questionnaire (no national average available).

\section{Item score distributions}

Item score distributions were examined for completeness and skewness. Missing value rates were generally 


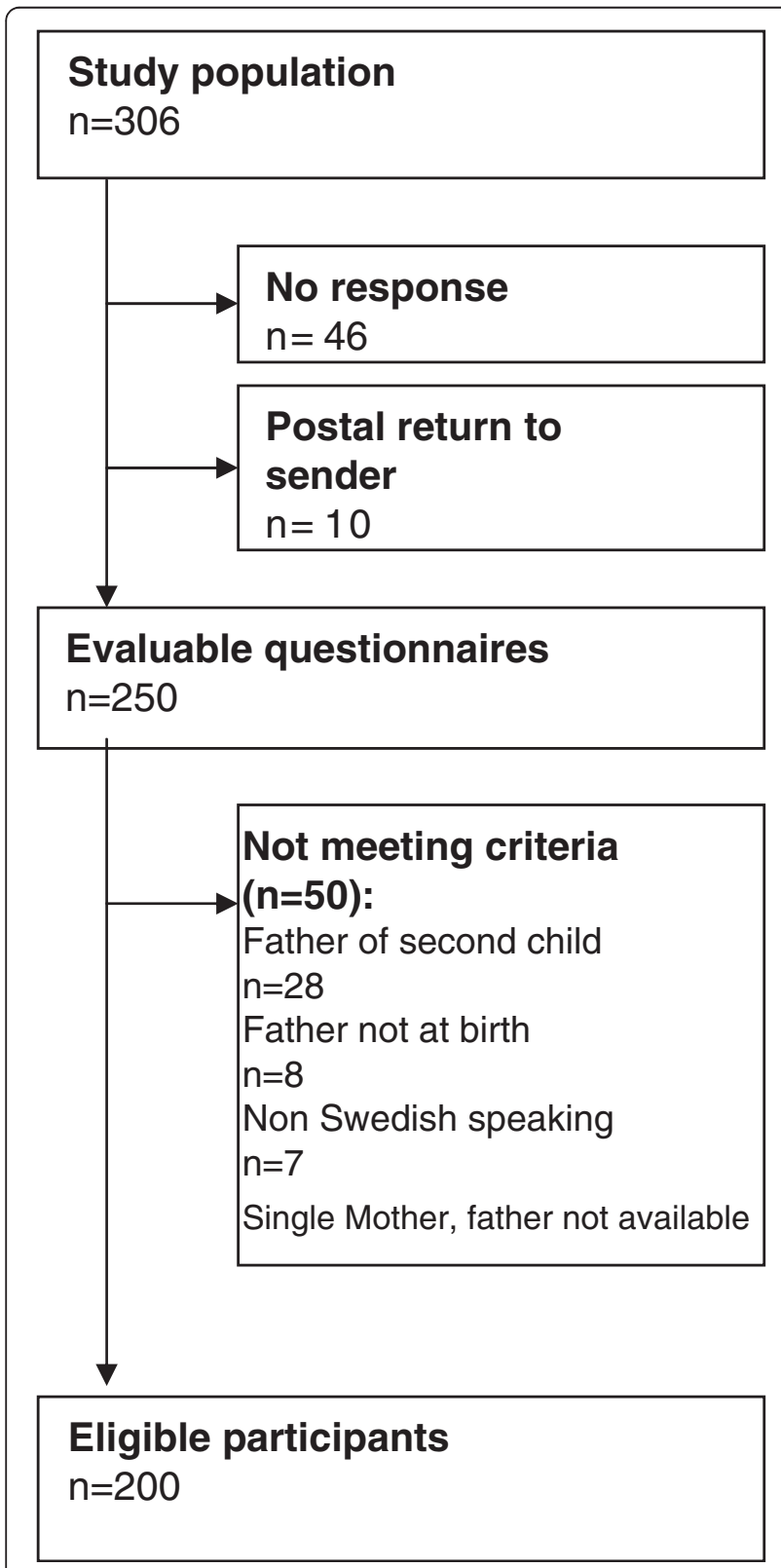

Figure 2 Flowchart of the study sample included in the analyses.

low for all items; but one item was excluded from further analysis (missing rate $=92 \%$ ), i.e.: I had opportunity to touch the baby's head before it was born'. Some items had extreme ceiling effects $(>90 \%)$ and were excluded from further analysis: 'I was given adequate information,' 'I was expected to give support,' My role was to hold and massage my partner', and 'I was just there, watching the birth'.

\section{Principal components analysis}

After excluding skewed items, a total of 29 items were entered in an initial principal components analysis. The
Table 1 Socio-demographic characteristics of the study group, $\mathbf{n}=\mathbf{2 0 0}$

\begin{tabular}{|c|c|c|}
\hline & n & $\%$ \\
\hline \multicolumn{3}{|l|}{ Marital status $(n=188)^{*}$} \\
\hline Married/ cohabiting & 185 & 97.95 \\
\hline Single & 3 & 1.5 \\
\hline \multicolumn{3}{|l|}{ Educational level $(n=187)$} \\
\hline Elementary school & 15 & 7.1 \\
\hline High school & 81 & 41 \\
\hline University & 91 & 45 \\
\hline \multicolumn{3}{|l|}{ Mode of delivery $8(n=197)$} \\
\hline Vaginal birth & 145 & 72 \\
\hline Operational vaginal birth & 27 & 13.5 \\
\hline Caesarean Section & 25 & 12.5 \\
\hline \multicolumn{3}{|l|}{ Ethnic background $(n=196) * *$} \\
\hline Born in Sweden to Swedish parents & 155 & 79 \\
\hline Parents (1 or2) born outside Sweden & 46 & \\
\hline Born outside Sweden & 33 & 18 \\
\hline \multicolumn{3}{|l|}{ Preparation for Childbirth $(n=198) * *$} \\
\hline Antenatal clinic class & 158 & 79 \\
\hline Lamaze class & 30 & 15 \\
\hline Self study & 94 & 47 \\
\hline Consulted friends and family & 103 & 52 \\
\hline No preparation & 7 & 0.5 \\
\hline Mean age (SD) & $31.8(5.6)$ & \\
\hline
\end{tabular}

- $\mathrm{n}=$ number of fathers who answered the question.

** More than one alternative was possible.

analysis yielded nine factors with eigenvalues $>1$, which accounted for $62 \%$ of the variance (Table 2). However, of these factors five comprised only one or two items, and were judged not to be interpretable from a clinical perspective. Hence a four-factor solution was chosen. In this solution seven items had low or diffuse loadings and were omitted. Examples of these items were: 'I felt I was in the midwife's way', 'It didn't make any difference if I was there or not', 'I was mainly a spectator' and 'I was persuaded to participate during childbirth'. The remaining 22 items yielded 4 factors meeting extraction criteria and explaining $48.6 \%$ of the total variance: Worry, Information, Emotional support, and Acceptance. Worry (8 items; 20.5\% of variance) included items related to concerns about the well being of spouse and infant, inadequacies in giving support, own reactions, and fear of the unknown. Information (4 items, 15.6\%) comprised items tapping feelings of being prepared and receiving relevant information during childbirth. Emotional support (6 items, 6.5\%) concerned fathers' experiences of guidance, support and comfort provided by assisting personnel during 
Table 2 Factor analysis

\begin{tabular}{|c|c|c|c|c|}
\hline Items & Worry & Informed & Emotional support & Acceptance \\
\hline Worry about error & .82 & & & \\
\hline Worry about the child & .80 & & & \\
\hline Worry about wife/girlfriend & .72 & & & \\
\hline Worry about the unknown & .70 & & & \\
\hline Worry not capable to support & .61 & & & \\
\hline Worry about own reaction & .58 & & & \\
\hline I was frighten & .66 & & & \\
\hline Dispens to take part & .41 & & & \\
\hline I felt well informed & & .78 & & \\
\hline I felt well prepared & & .74 & & \\
\hline Enough information & & .66 & & \\
\hline Missing some information & & .65 & & \\
\hline Shown how to hold the baby & & & .66 & \\
\hline Encouraged to hold the baby & & & .62 & \\
\hline The HCPs* made sure I was ok & & & .61 & \\
\hline The HCPs comforted me & & & .50 & \\
\hline The HCPs gave me guidance in support & & & .45 & \\
\hline The HCPs replaced me when I needed & & & .41 & \\
\hline The HCPs received me well & & & & .76 \\
\hline The HCP received me well via telephone & & & & .70 \\
\hline The HCPs gave me positive attention & & & & .47 \\
\hline I felt accepted at the delivery ward & & & & .63 \\
\hline
\end{tabular}

HCPs $=$ Health Care Providers.

childbirth. Acceptance (4 items, 5.9\%) comprised items regarding fathers' impressions of how they were received, treated and acknowledged by health care providers (Table 2).

\section{Multitrait- scaling analysis}

The Multitrait-scaling analysis showed that scaling assumptions were adequately met for all dimensions (Table 3). Item-scale correlations exceeded 0.40 for nearly all items and those less than 0.40 were still higher with their own scale than with competing scales (item discriminant validity). Item scale correlations, means and variances showed that items contributed roughly equally to its hypothesized scale. Cronbach's alpha coefficients were acceptable for group analyses $(>0.70)$ in two scales (Worry, 0.82 and Information 0.73) and slightly lower in Emotional support (0.65) and Acceptance (0.66) (Table 3).

\section{Table 3 Test of scaling assumptions}

\begin{tabular}{|c|c|c|c|c|c|}
\hline \multirow[t]{3}{*}{ Scale } & \multicolumn{5}{|c|}{ Item internal consistency } \\
\hline & \multirow[b]{2}{*}{$\begin{array}{l}\text { Item-scale } \\
\text { Correlation* }\end{array}$} & \multirow[b]{2}{*}{$\begin{array}{l}\text { Cronbachs } \\
\text { alpha** }\end{array}$} & \multirow{2}{*}{$\begin{array}{l}\text { Item } \\
\text { Discriminant } \\
\text { validity }\end{array}$} & \multirow{2}{*}{$\begin{array}{l}\text { Item } \\
\begin{array}{l}\text { Correlations } \\
\text { range }\end{array}\end{array}$} & \multirow{2}{*}{$\begin{array}{l}\text { Item } \\
\text { Variance, SD } \\
\text { range } * * * *\end{array}$} \\
\hline & & & & & \\
\hline Worry & $7 / 8$ & 0.82 & $8 / 8$ & $0.34-0.67$ & $0.78-1.17$ \\
\hline Information & $4 / 4$ & 0.73 & $4 / 4$ & $0.45-0.57$ & $0.74-0.98$ \\
\hline \multicolumn{6}{|l|}{ Emotional } \\
\hline support & $3 / 6$ & 0.65 & $6 / 6$ & $0.26-0.48$ & $0.92-1.22$ \\
\hline Acceptance & $4 / 4$ & 0.66 & $3 / 4$ & $0.40-0.49$ & $0.72-0.97$ \\
\hline
\end{tabular}

* Item scale correlation $>0.40$, corrected for overlap / number of correlations.

** Scale internal consistency reliability (Cronbachs alpha).

*** Item-scale correlations roughly the same for all items in the scale.

**** Item in hypothesized scale have roughly equal variances. 
Table 4 Differences in subscale scores between modes of delivery and native Swedes vs. immigrants

\begin{tabular}{|c|c|c|c|c|c|c|c|c|c|}
\hline Dimension & $\begin{array}{l}\text { Vaginal delivery } \\
\text { (a) }(n=145)\end{array}$ & $\begin{array}{l}\text { Instrumental } \\
\text { delivery (b) } \\
(n=26)\end{array}$ & $\begin{array}{l}\text { Acute Caesarean } \\
\text { Section }(c) \\
(n=25)\end{array}$ & $\begin{array}{l}\text { ANOVA, } \\
\text { p-value }\end{array}$ & $\begin{array}{l}\text { Post } \\
\text { hoc } \\
\text { a-c }\end{array}$ & $\begin{array}{l}\text { Post } \\
\text { hoc } \\
\text { a-b }\end{array}$ & $\begin{array}{l}\text { Native } \\
\text { Swedes }\end{array}$ & Immigrants & P-value* \\
\hline Worry & 221 & 2.73 & 2.77 & 0.000 & 0000 & 0.001 & 2.29 & 2.62 & 0.013 \\
\hline Information & 1.72 & 1.92 & 2.03 & 0.032 & 0.049 & 0.28 & 1.76 & 1.93 & 0.12 \\
\hline Emotional support & 2.36 & 2.37 & 2.39 & 0.96 & 0.96 & 0.99 & 2.38 & 2.32 & 0.64 \\
\hline Acceptance & 1.37 & 1.50 & 1.58 & 0.18 & 0.16 & 0.94 & 1.41 & 1.41 & 0.96 \\
\hline
\end{tabular}

Range: 1-4, were 1 was the best, and 4 the worst alternative.

\section{Known-groups validation}

The discriminant validity of the questionnaire was evaluated by comparing mean scores on each subscale between fathers whose child was delivered with caesarean section (= CS) or instrumental birth (=ID) and those whose child was vaginally born. It is known from earlier research that CS and ID fathers are more worried and less prepared for the situation [23,30]. As expected, the CS and ID group had significantly higher scores $(\mathrm{p}=0.000)$ on the factor Worry and the CS had significantly higher scores on the factor Information ( $\mathrm{p}=0.03$ ).

Also as expected [31,37], the youngest fathers had significantly higher scores on the factors Emotional support $(\mathrm{p}=0.40)$ and Acceptance $(\mathrm{p}=0.41)$ than the oldest fathers. A difference between immigrant fathers versus native Swedish fathers [33,34] was also found, where the immigrant fathers had significantly higher scores on the factor Worry $(\mathrm{p}=0.013)$. However, Swedish born fathers with one or two parents born outside Sweden did not significantly differ from those with Swedish born parents. There were no significant differences in any scale due to the father's educational level (Table 4, 5).

\section{Discussion}

This study reports on the development and validation of an instrument designed to assess first-time fathers' experiences of childbirth. Currently, the only available validated instrument [6] assesses fathers' experiences in a broad perspective, including perceived competence of healthcare providers and the environment in the delivery ward. Moreover, it focuses on fathers in general rather than explicitly on first-time fathers.
Domains and items comprising the instrument were principally derived directly from interviews with firsttime fathers, supplemented by literature searches and a focus group interview with experienced midwives. The focus group interview added one item, but it was subsequently excluded in the factor analysis. The literature search was made mainly in medical and nursing databases; however, extending the search to other databases, such as the Sociological Abstracts, might conceivably have added more domains. A draft version of the questionnaire was evaluated by an expert panel and pilot tested in a group of first-time fathers. A revised version was completed by 200 first-time fathers (81\% response rate).

Principal components analysis of the questionnaire yielded four domains, reflecting the complexity and multidimensionality of first-time fathers' experiences of childbirth: Worry, Information, Emotional support and Acceptance (Table 2). Of the five initial domains identified in our interviews, one could not be corroborated in these analyses, namely 'support to the woman'. This was due primarily to the fact that many of the items in this domain had extremely high ceiling effects or items hypothesized to belong to this domain were absorbed by the Emotional support domain.

Most of the variance in the instrument was explained by the domain Worry, which confirms the importance attributed to this domain in earlier and more recent research [38,39]. Interestingly, this domain, comprising items about worries and anxiety about the mother and child, corresponds well with the strongest dimension, Discomfort, in [6]. The importance of the second

Table 5 Differences in subscale scores between education and age groups

\begin{tabular}{|c|c|c|c|c|c|c|c|c|c|c|}
\hline Dimension & Comprehensive school & High school & University & $\begin{array}{l}\text { ANOVA } \\
\text { p-value }\end{array}$ & $\begin{array}{l}\text { Age } 1 \\
<26 \\
n=31\end{array}$ & $\begin{array}{l}\text { Age } 2 \\
26-31 \\
n=69\end{array}$ & $\begin{array}{l}\text { Age } 3 \\
31-37 \\
n=70\end{array}$ & $\begin{array}{l}\text { Age } 4 \\
>37 \\
n=26\end{array}$ & $\begin{array}{l}\text { ANOVA } \\
\text { p-value }\end{array}$ & $\begin{array}{l}\text { Post } \\
\text { hoc } \\
1-4\end{array}$ \\
\hline Worry & 2.54 & 2.32 & 2.30 & 0.47 & 2.34 & 2.32 & 2.26 & 2.66 & 0.10 & 0.34 \\
\hline Information & 1.66 & 1.81 & 1.78 & 0.67 & 1.85 & 1.84 & 1.74 & 1.66 & 0.49 & 0.63 \\
\hline Emotional & 2.14 & 2.48 & 2.31 & 0.075 & 2.65 & 2.32 & 2.34 & 2.22 & 0.04 & 0.04 \\
\hline \multicolumn{11}{|l|}{ support } \\
\hline Acceptance & 1.45 & 1.50 & 1.32 & 0.083 & 1.61 & 1.37 & 1.42 & 1.21 & 0.04 & 0.02 \\
\hline
\end{tabular}

Range: $1-4$, were 1 was the best, and 4 the worst alternative. 
domain, Information, has also been confirmed in research $[40,41]$. Support has often been emphasized in research on the childbirth experiences of fathers in general [13,42,43]; however, our Emotional support domain also taps aspects related to guidance and comfort, which has not been accentuated in previous questionnaires. It is noteworthy that the fourth domain, Acceptance, accounted for a significant proportion of the variance. Despite the fact that fathers in Sweden have been present during childbirth for decades, the fact that $A c$ ceptance represented an independent domain suggests that they are still not always well received $[18,22,44]$.

Some items regarding fathers' participation in childbirth and support to their partners had extreme ceiling effects $(>90 \%$ endorsed the most positive response choice) and were omitted since they were judged to weaken the discriminant validity of the instrument. Possible explanations for the highly positive ratings on these items may be either that father's see their participation and support during childbirth as self-evident or that they wish to present themselves in a positive light and thus respond in a socially desirable manner. Moreover, some of the items about fathers' participation were derived from studies conducted nearly 15 years ago and in a different cultural setting $[12,42]$. Hence, the items may not be relevant or appropriate for Swedish fathers or for current childbirth practices.

The domains Emotional support and Acceptance did not meet conventional reliability standards for group comparisons (Cronbach alpha $>0.70$ ). Excluding one or two items in these domains would have yielded acceptable alphas; however, we retained these items because they were considered to be clinically relevant. Multitraitscaling analysis confirmed that these domains otherwise adequately met scaling assumptions for aggregating item ratings to scale scores and known-groups analyses supported their external validity.

Known groups analyses showed that the instrument could discriminate between subgroups of fathers known to differ on key clinical or socio demographic variables, specifically caesarean vs vaginal birth, older vs younger fathers, Swedish-born vs immigrant fathers, and high vs low education level. Supporting its discriminant validity, significant differences in the expected direction were found in comparisons between these groups, with the exception education level. However, educational level may be a poor indicator of socioeconomic status, which has previously been found to be associated with fathers' experiences of childbirth $[3,45,46]$.

Due to the fact that there is no paternity registry in Sweden, the questionnaire was mailed to the mothers of the newborn with the instruction to give it to the infant's father. This approach may have biased our sample in favour of fathers who currently live with or are on good terms with the mothers. This potential bias may be important since fathers with poor marital relationships have been shown to report higher levels of psychological distress and depressive symptomatology $[40,41]$. Hence, there may be a need to further validate the questionnaire in a more heterogeneous sample, with respect to marital status.

A strength of the study was that the domains and most items were based on interviews with first-time fathers [15-17], supplemented by a literature search and focus group discussions with experienced midwives. The fact that the items were evaluated iteratively for face validity with regard to comprehensiveness, relevance and comprehension in a panel of experts in paternity research and in a pilot study of first time fathers also supports the validity of the questionnaire. Another strength of the study was the relatively large $(n=296)$ sample size and the high response rate (81\%).

\section{Conclusions}

Our results suggest that this instrument adequately assesses important aspects of first-time fathers' experiences of childbirth. It may serve as a useful and sensitive tool for assessing first-time fathers' experiences and needs at labour wards and may be used to help identify fathers in need of extra support and counselling following negative birth experiences. However, more work is needed to improve the reliability of the instrument, particularly regarding the item content of the domains Emotional support and Acceptance, before it can be used with confidence for screening purposes.

\section{Competing interests}

The authors declare that they have no competing interests.

\section{Authors' contributions}

ÅP participated in the design of the study, data collection and analyses, writing the first draft of the manuscript and thereafter in revising and developing the manuscript in collaboration with the co-authors. MB participated in the design of the study and the development of the manuscript and supervision; CT participated in the design of the study, data analyses, supervision and manuscript preparation; and ALH participated in the design of the study and development of manuscript.

\section{Acknowledgement}

The authors want to express their gratitude to The Local Board of Research and Development for Gothenburg and Södra Bohuslän and Strategic Funds of The Institute of Health and Care Sciences, Sahlgrenska Academy at Göteborg University, for financial support

Received: 19 August 2011 Accepted: 24 April 2012

Published: 17 May 2012

\section{References}

1. Condon JT, Boyce P, Corkindale CJ: The First-Time Fathers Study: a prospective study of the mental health and wellbeing of men during the transition to parenthood. Aust N Z J Psychiatry 2004, 38(1/2):56-64.

2. Deave $\mathrm{T}$ : The transition to parenthood: what does it mean for fathers? J Adv Nurs 2008, 63(6):626. 
3. Genesoni $L$, Tallandini MA: Men's psychological transition to fatherhood: An analysis of the literature, 1989-2008. Birth (Berkeley, Calif) 2009, 36(4):305-317

4. Palkovitz R: Fathers' motives for birth attendance. Matern Child Nurs J 1987, 16(2):123-129.

5. Nichols MR: Paternal perspectives of the childbirth experience. Matern Child Nurs J 1993, 21(3):99-108.

6. Vehvilainen-Julkunen K, Liukkonen A: Fathers' experiences of childbirth Midwifery 1998, 14(1):10-17.

7. Draper J: Men's passage to fatherhood: an analysis of the contemporary relevance of transition theory. Nurs Inq 2003, 10(1):66-77.

8. Cronenwett LR, Newmark LL: Fathers' responses to childbirth. Nurs Res 1974, 23(3):210-217.

9. Dragonas TG: Greek fathers' participation in labour and care of the infant. Scand J Caring Sci 1992, 6(3):151-159.

10. David M: Ethnic Turkish fathers in birth support roles in a berlin labour and delivery room-motives, preparation and incidence in a 10-year comparison. J Psychosom Obstet Gynecol 2009, 30(1):5-10.

11. Lamb ME: The role of the father in child development. 4th edition. Hoboken, NJ: Wiley; 2003.

12. Chandler S, Field PA: Becoming a father: first-time fathers' experience of labor and delivery. J Nurse Midwifery 1997, 42(1):17-24.

13. Somers-Smith MJ: A place for the partner? Expectations and experiences of support during childbirth. Midwifery 1999, 15(2):101-108.

14. Backstrom C, Hertfelt Wahn E: Support during labour: first-time fathers' descriptions of requested and received support during the birth of their child. Midwifery 2009.

15. Premberg A, Hellstrom AL, Berg M: Experiences of the first year as father. Scand J Caring Sci 2008, 22(1):56-63.

16. Premberg A, Lundgren I: Fathers' Experiences of Childbirth Education. J Perinat Educ 2006, 15:21-28.

17. Premberg A, Carlsson G, Hellstrom AL, Berg M: First-time fathers' experiences of childbirth-A phenomenological study. Midwifery 2010.

18. Ellberg $L$, Hogberg $U$, Lindh V: 'We feel like one, they see us as two': new parents' discontent with postnatal care. Midwifery 2008.

19. Bradley R, Slade P, Leviston A: Low rates of PTSD in men attending childbirth: a preliminary study. Br J Clin Psychol 2008, 47(Part 3):295-302.

20. Schumacher M: Bringing birth-related paternal depression to the fore. Women Birth 2008, 21(2):65-70.

21. McVeigh CA, Baafi M, Williamson M: Functional status after fatherhood: an Australian study. J Obstet Gynecol Neonatal Nurs 2002, 31(2):165-171.

22. Singh D: What men think of midwives. RCM Midwives 2003, 6(2):70.

23. Rosich-Medina A: Paternal experiences of pregnancy and labour. $\mathrm{Br} J$ Midwifery 2007, 15(2):66.

24. Persson EK, Fridlund B, Dykes A-K: Parents postnatal sense of security (PPSS): development of the PPSS instrument. Scand J Caring Sci 2007, 21(1):118-125

25. Hollins Martin CJ: A tool to measure fathers' attitudes and needs in relation to birth. Br J Midwifery 2008, 16(7):432-437.

26. Salonen $A H$, Kaunonen $M$, Astedt-Kurki $P$, Jarvenpaa AL, Tarkka MT Development of an internet-based intervention for parents of infants. J Adv Nurs 2008, 64(1):60-72.

27. World Medical Association W: WMA Declaration of Helsinki - Ethical Principles for Medical Research Involving Human Subjects. 2008.

28. Fayers PM, Machin D: Quality of life: the assessment, analysis and interpretation of patient-reported outcomes. 2nd edition. Chichester: John Wiley; 2007.

29. Kerlinger FN: Foundations of behavioral research. 2nd edition. New York; London: Holt, Rinehart and Winston; 1973.

30. Chan KKL: How do fathers feel after accompanying their partners in labour and delivery?. J Obstet Gynaecol 2002, 22(1):11-15.

31. Fagan J, Bernd E, Whiteman V: Adolescent Fathers' Parenting Stress, Social Support, and Involvement with Infants. J Res Adolesc 2007, 17(1):1-22.

32. Buist A, Morse CA, Durkin S: Men's adjustment to fatherhood: implications for obstetric health care. J Obstet Gynecol Neonatal Nurs 2003, 32(2):172-180.

33. Ny P, Plantin L, Dejin-Karlsson E, Dykes A: The experience of Middle Eastern men living in Sweden of maternal and child health care and fatherhood: focus-group discussions and content analysis. Midwifery 2008, 24(3):281-290
34. Wiklund $H$, Aden AS, Högberg U, Wikman M, Dahlgren L: Somalis giving birth in Sweden: a challenge to culture and gender specific values and behaviours. Midwifery 2000, 16(2):105-115.

35. Ware JE Jr, Harris WJ, Gandek B, Rogers BW, Reece PR: MAP-R for Windows: Multitrait/Multi-Item Analysis Program. Boston: Health Assessment Lab; 1997.

36. Statistiska centralbyrån: Statistisk årsbok för Sverige. Årg. 96(2010) Stockholm: Statistiska centralbyrån; 2010.

37. Bunting L, McAuley C: Research review: teenage pregnancy and parenthood: the role of fathers. Child Fam Soc Work 2004, 9(3):295-303.

38. Berry LM: Realistic expectations of the labor coach. J Obstet Gynecol Neonatal Nurs 1988, 17(5):354-355.

39. Eriksson C: Men's experiences of intense fear related to childbirth investigated in a Swedish qualitative study. J Mens Health Gend 2007, 4(4):409-418.

40. Boyce P, Condon J, Barton J, Corkindale C: First-Time Fathers' Study: psychological distress in expectant fathers during pregnancy. Aust N Z J Psychiatry 2007, 41(9):718-725.

41. Greenhalgh R, Slade P, Spiby H: Fathers' coping style, antenatal preparation, and experiences of labor and the postpartum. Birth 2000, 27(3):177-184.

42. Chapman L: Searching: expectant fathers' experiences during labor and birth. J Perinat Neonatal Nurs 1991, 4(4):21-29.

43. Draper J: Whose welfare in the labour room? A discussion of the increasing trend of fathers' birth attendance. Midwifery 1997, 13(3):132-138

44. de Montigny F, Lacharit C: Fathers' perceptions of the immediate postpartal period. J Obstet Gynecol Neonatal Nurs 2004, 33(3):328-339.

45. Johansson T, Klinth R: Caring Fathers: The Ideology of Gender Equality and Masculine Positions. Men Masculinities 2007, 1097184X06291899.

46. Kao B, Gau M, Wu S, Kuo B, Lee TY: A comparative study of expectant parents' childbirth expectations. J Nurs Res 2004, 12(3):191-201.

doi:10.1186/1471-2393-12-35

Cite this article as: Premberg et al:: Father for the first time development and validation of a questionnaire to assess fathers experiences of first childbirth (FTFQ). BMC Pregnancy and Childbirth 2012 12:35.

\section{Submit your next manuscript to BioMed Central and take full advantage of:}

- Convenient online submission

- Thorough peer review

- No space constraints or color figure charges

- Immediate publication on acceptance

- Inclusion in PubMed, CAS, Scopus and Google Scholar

- Research which is freely available for redistribution 